Reseñas 


\section{Mojica, F. (2018). Los retos del talento humano en el posconflicto. Bogotá: Editorial. Fundación Universitaria San Mateo, ISBN 978-958-56900-2-8}

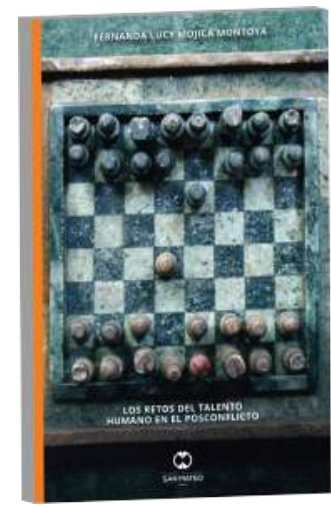

Hablar de conflicto interno armado en Colombia y, a su vez, conversar sobre la construcción de culturas de paz en escenarios organizacionales, han sido uno de los grandes desafíos en los que actores sociales, como el Estado, las comunidades, personas víctimas directas e indirectas de este conflicto, así como la academia, las empresas y grupos al margen de la ley, han tenido que enfrentar. Es una guerra de más de cincuenta 50 años que tiene como antecedente la colonización del territorio colombiano, en el que la apropiación de este se enmarca en lógicas y acciones de poder, donde el acceso a la tierra ha sido la raíz del conflicto. De manera que construir una cultura de paz lleva consigo la transformación de imaginarios sociales que trasciende la simple y llana acción social.

Bajo lo anterior, es importante mencionar que el conflicto interno armado en Colombia, como lo afirma el Centro Nacional de Memoria Histórica (2013), comienza a estructurarse en un primer periodo entre los años de 1958 y 1982 . Es caracterizado por la divergencia de tipo ideológica entre partidos políticos ${ }^{1}$, desatando de manera implícita la emergencia de grupos subversivos que deciden ir en contra de la burocracia estatal, con el ideal inicial de exigir la equidad en cuanto a las decisiones políticas, socialesy económicas dentro del territorio colombiano. Seguido de esto, en el lapso de 1982 y 1996, se desató una ola de violencia indiscriminada que dio origen a grupos, como lo fueron las Fuerzas Armadas Revolucionarias de Colombia (FARC) y el Ejercito de Liberación Nacional (ELN), trayendo consigo la implantación de negocios ilícitos como el narcotráfico.

Este fenómeno social, político y económico generó la desconfiguración del orden y control de todo el país, dando paso a la consolidación de las guerrillas y paramilitares, quienes fueron categorizados como los actores potenciales del conflicto. En este sentido, el gobierno emprendió medidas de tipo militar, en donde el

\footnotetext{
${ }^{1}$ Hecho histórico en Colombia denominado como Frente Nacional entre el partido Liberal y Conservador.
} 
uso indiscriminado de la fuerza trajo como consecuencia centenares de masacres, frente a las cuales a la actualidad, según la Unidad para las Víctimas (2018), se encuentran registradas históricamente 8.760.290 personas afectadas de las cuales 6.997 .066 han sido asistidas y reparadas por el Estado colombiano².

A partir de lo anterior, el 24 de noviembre de 2016 en Colombia se firmaron los acuerdos de paz entre el expresidente Juan Manuel Santos y el líder de las FARC, Rodrigo Londoño alías Timochenko. Este tiene como fin último "(...) construir una paz estable y duradera, con la participación de todos los colombianos y colombianas" (Acuerdo final para la terminación del conflicto y la construcción de un paz estable y duradera, 2016, p. 4). Dicho objetivo representa, de manera contundente, el papel los actores en esta construcción. Como lo afirma Kisielewski y LeDoux (2009), la participación de naturaleza democrática conduce a los actores sociales hacia la incidencia en decisiones de tipo social, organizacional, político y económico, en cuanto a acciones que conlleven comportamientos comunitarios enmarcados en contextos de paz.

Con base en esta contextualización histórica, que comprende la construcción social de escenarios en el posconflicto, se presenta el libro titulado Los retos del talento humano en el posconflicto de la docente investigadora Fernanda Lucy Mojica Montoya (2018). Este tiene como propósito identificar las estrategias implementadas por las organizaciones, en relación con el proceso de inclusión de actores sociales en esta coyuntura. De esta manera, se visualiza no solo desde la llana inserción, sino como un proceso gestado desde la convivencia e incidencia en los procedimientos empresariales: selección, contratación y clima organizacional.

Así pues, el libro brinda un estado del arte que describe las concepciones teóricas relacionadas con el talento humano desde la posición de varios autores. Posiciona el concepto como el proceso núcleo de las organizaciones. Allí, los colaboradores se comprenden desde la potencialización y consolidación de competencias, de manera

\footnotetext{
2 El análisis de estas cifras está sujeto a estudio, pues tan solo por referir, habría que preguntarse, por ejemplo: ¿qué tipo de reparación han recibido las víctimas de la masacre de El Salado?, aun cuando hasta el año 2016, esta masacre fue trasmitida por los medios de comunicación. Para más información remítase a la lectura de esta, a través del siguiente enlace: https://www.semana.com/nación/artículo/masacre-de-el-salado-comola-planearon-y-ejecutaron-los-paramilitares/557580
} 
que, en escenarios de posconflicto esta comprensión se convierte en un reto nuclear, implica el diseño e implementación de políticas públicas que permitan el acceso a opciones laborales, educativas y de emprendimiento. Esto, debido a que los colaboradores de una compañía son quienes, al construir escenarios de paz, logran adquirir compromisos y responsabilidades organizacionales en pro de su competitividad en el mercado.

Ahora bien, los resultados de este libro de investigación permiten concluir que el desarrollo de los procedimientos en talento humano, contribuyen con la disminución de la rotación de los colaboradores en las empresas. En este la capacitación es uno de los componentes esenciales en la formación y potencialización de competencias, aunado a la cohesión entre el proyecto de vida de excombatientes con estos planes de capacitación y formación.

Finalmente, es posible dilucidar que la construcción de culturas de paz en las organizaciones deben estar mediadas por una participación del Estado y de instituciones que promuevan este tipo de comportamientos. Allí diversas disciplinas convergen para realizar trabajos que generen como resultado la participación de las víctimas, los victimarios y la sociedad civil, ya que, como lo refiere la Declaración y Programa de Acción sobre una Cultura de Paz (1999) en el Artículo No. 2: "el progreso hacia el pleno desarrollo de una cultura de paz se logra por medio de valores, actitudes, comportamientos y estilos de vida propicios para el fomento de la paz entre las personas, los grupos y las naciones" (p. 3).

\section{Luisa Katherine Rojas Ávila}

Psicóloga

Coordinadora Investigación de Programa de la facultad de Ciencias Administrativas y Afines

\section{Lista de referencias}

Centro Nacional de Memoria Histórica. (2013) ¡Basta Ya! Colombia: Memoria de Guerra y Dignidad. Resumen. Bogotál Colombia. Recuperado de: http://www.centrodememoriahistorica.gov.co/ descargas/informes2013/bastaYa/resumen-ejecutivo-basta-ya.pdf. 
Oficina del Alto Comisionado para la Paz. (24 de agosto de 2016). Acuerdo final para la terminación del conflicto y la construcción de un paz estable y duradera. Recuperado de: https://es.scribd. com/document/322147291/24-08-2016acuerdofinalfinalfinal1472094587\#fullscreen\&from_embed

Kisielewski, M., \& LeDoux, T. F. (2009). Democratic Participation. In Handbook on Building Cultures of Peace (pp. 153-166). Springer New York.

Mojica Montoya, F. (2018). Los retos del talento humano en el conflicto. Bogotá: Editorial Fundación Universitaria San Mateo. Recuperado de https://palma.sanmateo.edu.co/

Organización de las Naciones Unidas. (1999). Declaración y Programa de Acción sobre una Cultura de Paz.

Ruiz, M. (30 de agosto de 2018). Fiesta de sangre: así fue la masacre de El Salado. Revista Semana. Recuperado de https://www.semana. com/nacion/articulo/masacre-de-el-salado-como-la-planearon-yejecutaron-los-paramilitares/557580

Unidad para la atención y reparación integral a las víctimas. (2017). Registro Único de Víctimas. Recuperado de: https://www.unidadvictimas.gov. co/es/registro-unico-de-victimas-ruv/37394 